\title{
Insertion of Totally Implantable Central Venous Access Devices by Surgeons
}

\author{
Hyeonjun An, Chun-Geun Ryu, Eun-Joo Jung, Hyun Jong Kang ${ }^{1}$, Jin Hee Paik, Jung-Hyun Yang ${ }^{1}$, \\ Dae-Yong Hwang
}

Department of Surgery, Colorectal Cancer Center, Konkuk University Medical Center, ${ }^{1}$ Department of Surgery, Breast Cancer Center, Konkuk University Medical Center, Konkuk University School of Medicine, Seoul, Korea

Purpose: The aim of this study is to evaluate the results for the insertion of totally implantable central venous access devices (TICVADs) by surgeons.

Methods: Total 397 patients, in whom TICVADs had been inserted for intravenous chemotherapy between September 2008 and June 2014, were pooled. This procedure was performed under local anesthesia in an operation room. The insertion site for the TICVAD was mainly in the right-side subclavian vein. In the case of breast cancer patients, the subclavian vein opposite the surgical site was used for insertion.

Results: The 397 patients included 73 males and 324 females. Primary malignant tumors were mainly colorectal and breast cancer. The mean operation time was 54 minutes (18-276 minutes). Operation-related complications occurred in 33 cases (8.3\%). Early complications developed in 15 cases with catheter malposition and puncture failure. Late complications, which developed after 24 hours, included inflammation in 6 cases, skin necrosis in 6 cases, hematoma in 3 cases, port malfunction in 1 case, port migration in 1 case, and intractable pain at the port site in 1 case.

Conclusion: Insertion of a TICVAD under local anesthesia by a surgeon is a relatively safe procedure. Meticulous undermining of the skin and carefully managing the TICVAD could minimize complications.

Keywords: Vascular access devices; Central venous catheterization; Maintenance chemotherapy

\section{INTRODUCTION}

The totally implantable central venous access device (TICVAD, DistriCATH 605PM, Districlass Medical SA, France) has commonly been used for patients who need chemotherapy or parenteral nutrition for a long time (Fig. 1). Insertion of the TICVAD has been widely adopted since the first implantation performed by Niederhuber et al. in 1982 (quoted from [1-3]). The TICVAD provides a reliable and stable parenteral route for frequent blood sampling and repetitive infusions, especially in the field of oncol-

Received: April 6, 2015 - Accepted: April 9, 2015

Correspondence to: Dae-Yong Hwang, M.D.

Department of Surgery, Colorectal Cancer Center, Konkuk University Medical Center, Konkuk University School of Medicine, 120 Neungdong-ro,

Gwangjin-gu, Seoul 143-729, Korea

Tel: +82-2-2030-5111, Fax: +82-2-2030-5112

E-mail: hwangcrc@kuh.ac.kr

(c) 2015 The Korean Society of Coloproctology

This is an open-access article distributed under the terms of the Creative Commons Attribution NonCommercial License (http://creativecommons.org/licenses/by-nc/3.0) which permits unrestricted noncommercial use, distribution, and reproduction in any medium, provided the original work is properly cited. ogy. The merits of the TICVAD are a safe route to the central vein, long-term maintenance, and comfort for the patient. To date, safe and easy-to-handle port systems have become an integral part of daily clinical routine in oncology. In general, the insertion of a TICVAD is usually conducted by an intervention radiologist or a surgeon. According to the practitioners, the preference for a particular procedure could be different, for example, ultrasound guidance or a blind technique for puncture of the target vein. Therefore, this study was designed to evaluate the results of TICVAD insertion using blind technique by a surgeon.

\section{METHODS}

\section{Patients and surgical procedures}

A total of 397 patients, who had undergone TICVAD insertion by surgeons (C.G.R. and H.J.K.) between September 2008 and June 2014 were pooled. They were mainly diagnosed as having breast and colorectal cancer, and the procedure was performed to establish a stable venous route for intravenous chemotherapy. The operation time was measured from the time the patient entered the 


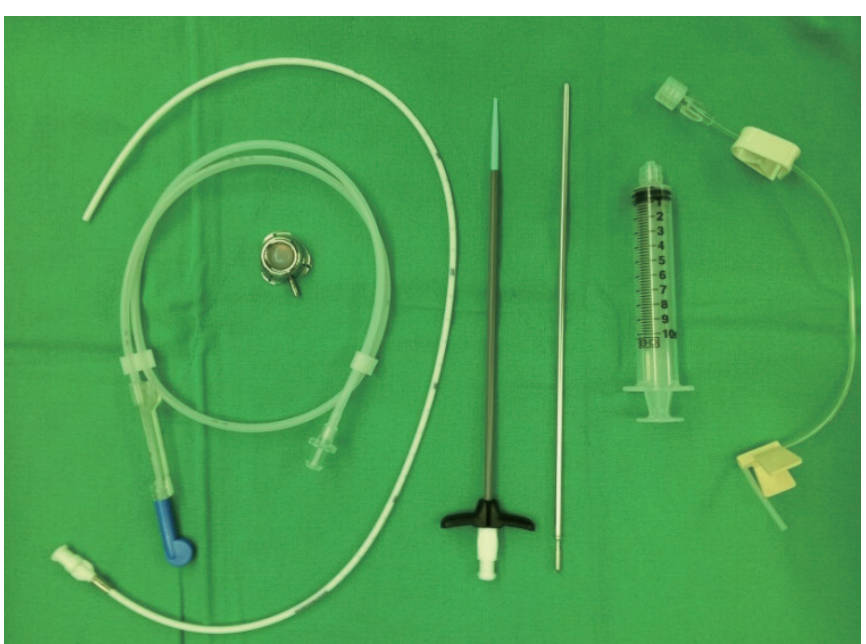

Fig. 1. Totally implantable central venous access device.

operation room to the time the aseptic dressing was applied after skin closure. Early complications were defined as problems arising within 24 hours after TICVAD insertion. Mostly, the right subclavian vein was chosen as the port site. In breast cancer patients, the port site was the contralateral side to the breast cancer lesion. The decision as to the target vein, subclavian or internal jugular vein, depended on the surgeon's preference.

\section{Procedure for TICVAD insertion}

The patient was in the supine position with his/her neck moved to the left if a right-sided vessel was chosen and to right if a leftsided vessel was chosen. Premedications like anxiolytics were not used. After betadine had been applied around the procedure site, the skin was draped in an aseptic manner. Under local anesthesia with $2 \%$ lidocaine, the skin was punctured at a point $1 \mathrm{~cm}$ inferior to the distal third of the right clavicle toward the suprasternal notch. A long needle was advanced along the dorsal surface of the clavicle bone with negative pressure. When venous blood was identified, the guide wire was placed through the needle by using a Seldinger maneuver. After the long needle had been removed and the skin had dilated, a catheter was inserted into subclavian vein along the guide wire. A venous catheter was filled with about $10 \mathrm{~mL}$ of diluted heparin (50 IU in $1 \mathrm{~mL}$ ) and clamped.

In the next step, a skin incision of about $2 \mathrm{~cm}$ was made for placement of the port chamber at a point on the lower $1 / 3$ of an imaginary line between the midclavicle and the nipple. A subcutaneous tunnel was made between the puncture site and the chamber site. The inserted venous catheter was connected to the chamber, and the function of the device was checked with aspiration of venous blood and injection of a diluted heparin solution. The chamber was fixed on the fascia of the pectoralis major muscle with a silk 2-0 suture. Bleeding control was performed meticulously, and the skin was approximated. After the procedure had been completed, a chest posteroanterior $\mathrm{x}$-ray (chest PA) was taken in all patients to check the position of the catheter's tip. No prophylactic intravenous antibiotic was used. Periodic heparin flushing of the TICVAD was performed.

\section{Procedure for TICVAD removal}

The patient was in the supine position with his/her neck moved to the left for a right-sided TICVAD and to the right for a leftsided TICVAD. After betadine had been applied around the previous incision site, the skin was draped in an aseptic manner. Under local anesthesia with $2 \%$ lidocaine, skin was incised along the previous scar on the port chamber. Subcutaneous tissue was dissected, and the chamber was exposed. The previous fixation to the pectoralis muscle was released by using a Bovie coagulator. The TICVAD was removed with careful manual compression on the catheter's insertion point. Bleeding control was performed meticulously, and the skin was approximated. No prophylactic intravenous antibiotic was used.

\section{RESULTS}

A total of 397 patients were enrolled: 73 males and 324 females. The mean age was 53.5 years (range, $27-83$ years). All TICVADs were inserted for the purpose of intravenous administration of chemotherapeutic agents. Primary malignant tumors were breast cancer in 270 cases, colorectal cancer in 117 cases, stomach cancer in 7 cases, ovarian cancer in 1 case, lymphoma in 1 case, and thyroid cancer in 1 case. The mean operation time was 54.3 minutes (range, 18-276 minutes). The characteristics of the patients are shown in Table 1. The TICVAD chamber's location was on right upper chest in 278 cases (70.0\%) and on left upper chest in 119 cases $(30.0 \%)$. The catheterized vein was the subclavian vein in 376 cases $(94.7 \%)$ and the internal jugular vein in 21 cases (5.3\%), as shown in Table 2.

Early complications occurred in 15 cases (3.8\%) and included

Table 1. Characteristics of patients

\begin{tabular}{lc}
\hline Characteristic & Value \\
\hline Gender & $73: 324$ \\
Male:female & $53.5 \pm 23.4(27-83)$ \\
Age (yr) & \\
Primary disease & $270(68.0)$ \\
Breast cancer & $117(29.5)$ \\
Colorectal cancer & $7(1.8)$ \\
Stomach cancer & $1(0.3)$ \\
Ovary cancer & $1(0.3)$ \\
Lymphoma & $1(0.3)$ \\
Thyroid cancer & $54.3 \pm 23.4(18-276)$ \\
Operation time (min)
\end{tabular}

Values are presented as mean \pm standard deviation (range) or number (\%). 
initial puncture failure and catheter malposition. In cases of puncture failure, patients were referred to interventional radiologists. Catheter malposition was defined as the catheter's tip via the subclavian vein being placed on the ipsilateral jugular vein. In these cases, the TICVAD was inserted via the ipsilateral internal jugular vein. Late complications occurred in 18 cases (4.5\%). Late complications, which were developed after 24 hours, included inflammation in 6 cases (port was removed), skin necrosis in 6 cases (port was removed with debridement of necrotic tissue), a hematoma in 3 cases (hematoma was evacuated with port removal), port malfunction in 1 case (port was removed), port migration in 1 case (port was reinserted), and intractable pain at the port site in 1 case (port was removed). Other complications, such as venous thrombosis and pneumothorax, did not occur. Table 3 presents the complications and their treatments.

Table 4 showed the profiles of patients with skin problems. All 6 patients had stage IV breast cancer, and chemotherapy with a palliative aim was being performed. The mean maintenance duration of the TICVAD was 10.2 months (range, 8.0-15.0 months). The risk factors for skin problems that we considered were mainly poor nutritional status and compromised immune status due to chemotherapy. In patent 2 , the field of radiotherapy for lung metastasis included the port insertion site.

\section{DISCUSSION}

In this study, complications occurred in 33 cases (8.3\%), with

Table 2. Anatomic site for venous access $(n=397)$

\begin{tabular}{ll}
\hline Location & \multicolumn{1}{c}{ No. $(\%)$} \\
\hline Right:left & $278(70.0): 119(30.0)$ \\
Subclavian vein:internal jugular vein & $376(94.7): 21(5.3)$ \\
Subclavian vein $(n=376)$ & \\
$\quad$ Right:left & $263(69.9): 113(30.1)$ \\
Internal jugular vein $(n=21)$ & \\
$\quad$ Right:left & $15(71.4): 6(28.6)$ \\
\hline
\end{tabular}

none of the complications being fatal. This result is similar to data reported in other studies (5\%-20\%) [1, 4-7] and is an acceptable complication rate.

In many studies about TICVAD, procedures were performed more commonly by interventional radiologists than by general surgeons and thoracic surgeons $[2,6,8-10]$. TICVAD insertion by interventional radiologists was performed under ultrasound guidance while the blind technique was used in procedures performed by surgeons $[2,4,6,8,9,11-13]$. We also used the blind technique, in which TICVAD insertion was performed by using the Seldinger maneuver without ultrasound guidance and chest PA, to check the catheter's position and to detect a pneumothorax or a hemothorax.

Of the early postprocedure complications, the most dangerous complications are a pneumothorax and a hemothorax $[7,11,13$, 14]. Fortunately, we did not experience these fatal events. Various rates of incidence of a pneumothorax have been reported. In the

Table 3. Complications of the TICVAD procedure

\begin{tabular}{lcl}
\hline Complication & No. (\%) & Treatment \\
\hline Total complications & $33(8.3)$ & \\
$\begin{array}{l}\text { Early complications } \\
\text { Catheter malposition }\end{array}$ & $3(0.8)$ & Reinsertion \\
$\begin{array}{l}\text { Puncture failure } \\
\text { Late complications }\end{array}$ & $12(3.0)$ & Reinsertion \\
Skin necrosis & & \\
Inflammation & $6(1.5)$ & Removal \\
Hematoma & $6(1.5)$ & Removal \\
Port migration & $3(0.8)$ & Removal \\
Intractable pain & $1(0.3)$ & Reinsertion \\
\hline Port malfunction & $1(0.3)$ & Removal \\
Pneumothorax & $1(0.3)$ & Removal \\
Hemothorax & $0(0)$ & \\
\hline
\end{tabular}

TICVAD, totally implantable central venous access device.

Table 4. Characteristics of patients with skin problems

\begin{tabular}{lccccl}
\hline No. & Sex/age & Primary malignancy & Stage & Maintenance period of TICVAD (mo) & Predictable risk factors for skin problem \\
\hline 1 & F/32 & Breast & IV & 12.5 & Poor nutritional status \\
& & & & Recurrent neutropenia due to chemotherapy \\
2 & F/55 & Breast & IV & 8.7 & Radiotherapy for lung metastasis \\
3 & F/39 & Breast & IV & 10.2 & Poor nutritional status \\
4 & F/52 & Breast & IV & 6.6 & Thin skin due to poor nutritional status \\
5 & F/39 & Breast & IV & 8.0 & Poor nutritional status \\
6 & & & & Recurrent neutropenia due to chemotherapy \\
\hline
\end{tabular}

TICVAD, totally implantable central venous access device. 
meta-analysis by Di Carlo et al. [7], the incidence of a pneumothorax was reported to be about $1.5 \%$. According to the different types of practitioners, this incidence rate was reported to be $0 \%-$ $4 \%$ for interventional radiologists and $0 \%-0.5 \%$ for surgeons [3-6, $12,13,15]$. That difference is probably due to the fact that surgeons are skilled in central venous catheterization under emergent situations, such as shock and sepsis.

Of the late complications, our study demonstrated that skin-related complications developed in 10 patients (2.5\%), with complications occurring in $47.6 \%$ of all patients. These included skin necrosis, hematomas, and intractable pain. All skin-related complications occurred in patients with TNM stage IV breast cancer, who were undergoing palliative chemotherapy. The median interval between TICVAD insertion and the development of a skin problem was 10.2 months (range, $8.0-15.0$ months). Especially in the patients with breast cancer, the TICVAD was inserted on the contralateral side of the breast cancer in consideration of radical axillary lymph node dissection and postoperative radiotherapy [13]. Cachexic and immunocompromised immunologic condition, radiation on the port site, and improper management of the TICVAD could cause skin problems in the long term after insertion. In addition, in the case of stage IV cancer, palliative radiotherapy could be considered for lung metastasis, regardless of the nature of the primary tumor. We needed to be aware that skin problems on the port site could develop as a result of radiotherapy on the chest. Recently, targeted agents have often been administrated with the chemotherapeutic agents for stage IV cancer patients. Some agents (i.e., antivascular endothelial growth factor antibody) can disturb the wound healing process and cause wound dehiscence or failure; however, we did not experience such complications. For the prevention of the skin problem on port insertion site, consideration for the further treatments is necessary [16].

Of the early complications, the incidence of puncture failure was $3.0 \%$. However, this is considered to a procedure-related problem rather than an early complication. Puncture failure occurred more frequently with less experienced practitioners. Thus, for the beginner practitioner, ultrasound guidance may be advantageous for finding the target vein. In the aspect of right- or left-side access, some studies suggest that patients with left-sided ports and catheter tips lying in the upper part of the vena cava are at high risk for severe thrombotic complications [17].

The main access veins to use for TICVAD insertion are the subclavian and the internal jugular vein $[2,6,8,10,14,16,18]$. In general, the safest route is well known to be the right internal jugular vein $[8,9,13]$. However, each access route has its own merits and demerits. Firstly, compared with accessing the subclavian vein, accessing the internal jugular vein has many advantages: less incidences of catheter loop formation, dislocation, occlusion, and thrombosis $[8,9,13]$. In addition, the internal jugular vein has a straight course to the superior vena cava, allowing for less contact of the catheter with the vessel wall and, thus, a lower risk of venous thrombosis [2]. However, using the subclavian vein has some advantages, which include the cosmetic superiority due to an incision only being made on the chest wall, more comfort by minimization of subcutaneous tunneling, and less procedure time $[5,12,18]$. The rates of local infection and sepsis were similar regardless of the vein accessed [14] .

In addition, several important precautions need to be considered when performing the procedure. The guide wire must be inserted below the right atrium because, in a few cases, irritation of the right atrium or the right ventricle has been reported as a possible risk for arrhythmia [5]. When selecting the internal jugular vein, the surgeon must confirm, by using ultrasound and/or a relatively smooth in-and-out of the guide wire, that the jugular vein, not the carotid artery, has been punctured $[5,11]$. Considering the purpose of a TICVAD for long-term usable intravenous access, we need to take many precautions to prevent long-term complications, such as inflammation, thrombosis, occlusion, and skin necrosis. Several strategies for the prevention of these complications, such as periodic heparin flushing of the TICVAD, use of specific noncoring needles, and aseptic management of the TICVAD, are available $[9,19,20]$. Basically, in managing the port site, the clinician has to check for inflammation, infection, skin necrosis, and thrombosis. More importantly, if the clinician suspects a complication, he/she should not hesitate to remove the port and use proper management, including the administration of intravenous antibiotics. The complication rate in our study was similar to those in other studies. However, early fatal complications, such as venous thrombosis, air embolism, hemothorax, and pneumothorax, did not occur in our study.

In conclusion, insertion of a totally implantable central venous device under local anesthesia by a surgeon is comparatively safe and can be performed without fatal complications. For long-term usage without late complications, proper management and careful follow-up by a clinician are necessary.

\section{CONFLICT OF INTEREST}

No potential conflict of interest relevant to this article was reported.

\section{REFERENCES}

1. Suslu H, Arslan G, Tural K. Venous port implantation in adult patients: retrospective evaluation. Agri 2012;24:32-6.

2. Ahn SJ, Kim HC, Chung JW, An SB, Yin YH, Jae HJ, et al. Ultrasound and fluoroscopy-guided placement of central venous ports via internal jugular vein: retrospective analysis of 1254 port implantations at a single center. Korean J Radiol 2012;13:314-23.

3. Kim JT, Oh TY, Chang WH, Jeong YK. Clinical review and analysis of complications of totally implantable venous access devices for chemotherapy. Med Oncol 2012;29:1361-4.

4. Seok JP, Kim YJ, Cho HM, Ryu HY, Hwang WJ, Sung TY. A retrospective clinical study: complications of totally implanted cen- 
tral venous access ports. Korean J Thorac Cardiovasc Surg 2014; 47:26-31.

5. Shin BS, Ahn M. Implantable central venous chemoport: comparision of results according to approach routes and methods. J Korean Radiol Soc 2003;49:165-71.

6. Song WG, Jin GY, Han YM, Yu HC. Central venous catheterization: comparison between interventional radiological procedure and blind surgical procedure. J Korean Radiol Soc 2002;47:467-72.

7. Di Carlo I, Pulvirenti E, Mannino M, Toro A. Increased use of percutaneous technique for totally implantable venous access devices. Is it real progress? A 27-year comprehensive review on early complications. Ann Surg Oncol 2010;17:1649-56.

8. Goltz JP, Petritsch B, Kirchner J, Hahn D, Kickuth R. Percutaneous image-guided implantation of totally implantable venous access ports in the forearm or the chest? A patients' point of view. Support Care Cancer 2013;21:505-10.

9. Walser EM. Venous access ports: indications, implantation technique, follow-up, and complications. Cardiovasc Intervent Radiol 2012;35:751-64.

10. Zaghal A, Khalife M, Mukherji D, El Majzoub N, Shamseddine A, Hoballah J, et al. Update on totally implantable venous access devices. Surg Oncol 2012;21:207-15.

11. Yaacob Y, Nguyen DV, Mohamed Z, Ralib AR, Zakaria R, Muda S. Image-guided chemoport insertion by interventional radiologists: A single-center experience on periprocedural complications. Indian J Radiol Imaging 2013;23:121-5.

12. Keum DY, Kim JB, Chae MC. Safety of a totally implantable central venous port system with percutaneous subclavian vein access. Korean J Thorac Cardiovasc Surg 2013;46:202-7.
13. Araujo C, Silva JP, Antunes P, Fernandes JM, Dias C, Pereira H, et al. A comparative study between two central veins for the introduction of totally implantable venous access devices in 1201 cancer patients. Eur J Surg Oncol 2008;34:222-6.

14. Ge X, Cavallazzi R, Li C, Pan SM, Wang YW, Wang FL. Central venous access sites for the prevention of venous thrombosis, stenosis and infection. Cochrane Database Syst Rev 2012;3:CD004084.

15. Knebel P, Lopez-Benitez R, Fischer L, Radeleff BA, Stampfl U, Bruckner $\mathrm{T}$, et al. Insertion of totally implantable venous access devices: an expertise-based, randomized, controlled trial (NCT00600444). Ann Surg 2011;253:1111-7.

16. Zawacki WJ, Walker TG, DeVasher E, Halpern EF, Waltman AC, Wicky ST, et al. Wound dehiscence or failure to heal following venous access port placement in patients receiving bevacizumab therapy. J Vasc Interv Radiol 2009;20:624-7.

17. Puel V, Caudry M, Le Metayer P, Baste JC, Midy D, Marsault C, et al. Superior vena cava thrombosis related to catheter malposition in cancer chemotherapy given through implanted ports. Cancer 1993;72:2248-52.

18. Plumhans C, Mahnken AH, Ocklenburg C, Keil S, Behrendt FF, Günther RW, et al. Jugular versus subclavian totally implantable access ports: catheter position, complications and intrainterventional pain perception. Eur J Radiol 2011;79:338-42.

19. Kim YS, Kim EY, Park WC. Spontaneous fracture and embolization of implantable venous access device in breast cancer patient. Korean J Vasc Endovasc Surg 2013;29:28-31.

20. Vescia S, Baumgartner AK, Jacobs VR, Kiechle-Bahat M, Rody A, Loibl S, et al. Management of venous port systems in oncology: a review of current evidence. Ann Oncol 2008;19:9-15. 